\title{
Investigating the duality of Inpp4b function in the cellular transformation of mouse fibroblasts
}

\author{
Emily Marie Mangialardi ${ }^{1}$, Keyue Chen ${ }^{1}$, Brittany Salmon ${ }^{1}$, Jean Vacher $^{2}$ and \\ Leonardo Salmena ${ }^{1,3}$ \\ ${ }^{1}$ Department of Pharmacology and Toxicology, University of Toronto, Toronto, Ontario, Canada \\ ${ }^{2}$ Institut de Recherches Cliniques de Montréal, Département de Médecine, Université de Montréal, Montréal, Québec, Canada \\ ${ }^{3}$ Princess Margaret Cancer Centre, University Health Network, Toronto, Ontario, Canada \\ Correspondence to: Leonardo Salmena, email: leonardo.salmena@utoronto.ca
}

Keywords: Inpp4b; MEF; RAS; El A; SV40-T-Large

Received: March 22, $2019 \quad$ Accepted: October 19, $2019 \quad$ Published: October 29, 2019

Copyright: Mangialardi et al. This is an open-access article distributed under the terms of the Creative Commons Attribution License 3.0 (CC BY 3.0), which permits unrestricted use, distribution, and reproduction in any medium, provided the original author and source are credited.

\section{ABSTRACT}

Inositol Polyphosphate 4-Phosphatase, Type II (INPP4B) is a tumour suppressor in breast, ovarian, prostate, thyroid and other cancers, attributed to its ability to reduce oncogenic Akt-signaling. However, emerging studies show that INPP4B also has tumour-promoting properties in cancers including acute myeloid leukemia, colon cancer, melanoma and breast cancer. Together these findings suggest that INPP4B may be a context dependent cancer gene. Whether INPP4B functions solely in a tumour suppressing or tumour promoting manner, or both in non-transformed cells is currently not clear. In this study, consequences of deficiency and overexpression of INPP4B on cellular transformation was investigated using a mouse embryonic fibroblast (MEF) model of cellular transformation. We observed that neither deficiency nor overexpression of INPP4B was sufficient to induce neoplastic transformation, alone or in combination with $H-R^{1 / 2}$ or E1A overexpression. However, Inpp4bdeficiency did cooperate with SV4O T-Large-mediated cellular transformation, a finding which was associated with increased phosphorylated-Akt levels. Transformation and phosphorylated-Akt levels were dampened upon overexpression of INPP4B in SV40 T-Large-MEF. Together, our findings support a model where INPP4B function suppresses transformation mediated by SV4O T-Large, but is inconsequential for Ras and $E 1 A$ mediated transformation.

\section{INTRODUCTION}

The phosphoinositide-3-kinase (PI3K) signaling pathway regulates cell survival, proliferation, metabolism and various other processes linked to cell growth. Human cancers frequently acquire mutations resulting in aberrant activation of PI3K signaling which is often associated with increased tumour progression and resistance to cancer therapies. The PI3K pathway is activated by growth-factor mediated activation of receptor tyrosine kinases (RTKs) and G protein-coupled receptors (GPCRs) which transduce signals through class I PI3K via phosphorylation of the 3-hydroxyl group of the inositol ring of phosphatidylinositol-4,5-bisphosphate $\left[\operatorname{PtdIns}(4,5) \mathrm{P}_{2}\right]$ to generate phosphatidylinositol-3,4,5- trisphosphate $\left(\operatorname{PtdIns}(3,4,5) \mathrm{P}_{3}\left[\mathrm{PIP}_{3}\right]\right)[1,2] . \mathrm{PIP}_{3}$ is subsequently dephosphorylated by either PTEN to form phosphatidylinositol-4,5-bisphosphate $\left[\operatorname{PtdIns}(4,5) \mathrm{P}_{2}\right]$ or by SHIP phosphatases to form phosphatidylinositol3,4-bisphosphate $\left[\operatorname{PtdIns}(3,4) \mathrm{P}_{2}\right]$. The 3'phosphorylated phosphatidylinositols like $\mathrm{PIP}_{3}$ and $\operatorname{Ptd} \operatorname{Ins}(3,4) \mathrm{P}_{2}$ recruit cytosolic proteins containing pleckstrin homology $(\mathrm{PH})$ domains, such as the serine/threonine kinase Akt. Once recruited to membranes, the kinase activity of Akt is activated by phosphorylation to promote downstream signaling to cell survival, growth, proliferation, cell migration and angiogenesis, through phosphorylation of specific intracellular protein substrates [3].

Inositol Polyphosphate 4-Phosphatase, Type II (INPP4B), a lipid phosphatase that preferentially 
hydrolyzes PtdIns $(3,4) \mathrm{P}_{2}$ to generate phosphatidylinositol3-monophosphate [PtdIns(3)P], was characterized as a gene with a key role in PI3K pathway signaling [4]. Since both PtdIns $(3,4) \mathrm{P}_{2}$ and $\mathrm{PIP}_{3}$ promote Akt recruitment to the plasma membrane, INPP4B was predicted to act as a tumour suppressor by inhibiting Akt recruitment, activation and thus downstream PI3K pathway signaling [5-8]. The first evidence characterizing INPP $4 B$ as a gene with importance in cancer was from a RNA interference screen in immortalized human mammary epithelial cells (HMEC) designed to identify candidate tumour suppressors [9]. Several studies have subsequently validated a tumour suppressor role for INPP $4 B$ in breast, ovarian, skin, and prostate cancer among others [10, $4,8,11-23]$. In these studies, INPP4B loss resulted in elevated Akt activation, increased cell survival and a more aggressive growth phenotypes associated with poor outcomes for cancer patients $[13,16,24]$. These findings for INPP4B contribute to the increasing role of phosphoinositide phosphatases other than PTEN in cancer; these include the INPP5-family members such as INPP5J/PIPP, INPP5D/SHIP1, INPPL1/SHIP2, and INPP5E [25-29]. Notably, despite the abundance of clinical data supporting a tumour suppressor role for INPP4B, there is no evidence that Inpp $4 b$ deletion alone in mouse models leads to tumour formation [17, 19, 30]. However when Inpp $4 b$ loss was combined with Pten heterozygosity, it altered the penetrance of the Ptenspectrum of tumours, and notably malignant thyroid cancer was observed $[17,19,30]$. Thus it has been suggested that INPP4B may be a tumour suppressor in the context of PTEN loss, and may have weak tumour suppressive function otherwise [31].

Conversely, emerging findings in malignancies including acute myeloid leukemia (AML), colon cancer, melanoma and breast cancer among others suggest that overexpression of $I N P P 4 B$ is also associated with promoting aggressive cancer phenotypes [32-36]. Signaling downstream of PtdIns(3)P has been explored as a possible mechanism. For instance, PtdIns(3)P mediated activation of Serum/Glucocorticoid Regulated Kinase Family Member 3 (SGK-3) was observed downstream of INPP4B overexpression in some cancers [34, 36-39]. Moreover, PtdIns(3)P has very important cellular roles, which include endosomal trafficking and autophagy which are currently unexplored in the context of INPP4B overexpression [40]. Moreover, INPP4B was reported to have both tumour promoting and tumour suppressing features in different subsets of the same cancer. For instance in melanoma and breast cancer, both INPP $4 B$ loss and $I N P P 4 B$ overexpression were associated with downstream oncogenic signaling through Akt and SGK3, respectively $[8,37,38,41]$. Altogether, these findings point to a putative contextual role for INPP4B in cancer [42, 43]. Nevertheless, mechanisms underlying the context-dependent cancer functions of INPP4B remain to be elucidated.
A growing body of evidence links altered levels of INPP $4 B$ expression to the progression of cancer. However, a role for INPP4B in the transformation of primary cells remains unexplored. Herein, we sought to investigate the consequences of Inpp $4 b$-deficiency and INPP $4 B$-overexpression on the cellular transformation of primary $\mathrm{MEF}$ in combination with oncogenic drivers including $H$-Ras ${ }^{V 12}, E 1 A$ or SV40 T-Large. Exploring a role for Inpp $4 b$ in $\mathrm{MEF}$ transformation may provide insight on whether co-operating driver mutational signaling will alter Inpp $4 b$ context dependent outcome in tumourigenesis.

\section{RESULTS}

\section{Characterization of primary $\operatorname{Inpp} 4 b^{+/+}, \operatorname{Inpp} 4 b^{+/-}$ and Inpp $4 b^{-/} \mathrm{MEF}$}

To investigate the role of Inpp $4 b$ loss on cellular transformation we generated E13.5 MEF from a constitutive Inpp 4b exon 10 knockout (Inpp4b-/) mouse model [30]. PCR genotyping of cultured MEFs derived from timed-matings of $\operatorname{Inpp} 4 b^{+/}$mice was performed to determine Inpp $4 b^{+/+}$, Inpp $4 b^{+/}$or Inpp $4 b^{-/-}$ genotypes (Figure 1A). RT-QPCR and immunoblots were performed to validate loss of both transcript and protein levels of Inpp4b in Inpp $4 b^{-/}$MEF (Figure 1B). Growth characteristics of primary MEF was evaluated in short term growth assays where we observed no significant differences in the mean growth rates of $\operatorname{Inpp} 4 b^{+/+}$, Inpp $4 b^{+/-}$and Inpp $4 b^{-/}$MEF (Figure 1C). Similarly, long term clonogenic growth potential was tested in primary Inpp $4 b^{+/+}$and Inpp $4 b^{-/}$MEF. After 11 days of growth, only sparse spontaneous clone formation was observed in both Inpp $4 b^{+/+}$and Inpp $4 b^{-/} \mathrm{MEF}$, with no measurable difference between genotypes (Figure 1D). Finally, neither Inpp $4 b^{+/+}$nor Inpp $4 b^{-/-}$MEF were observed to grow as anchorage independent colonies in soft agar (Figure 1E).

To investigate the necessity for Inpp $4 b$ in cellular transformation, we examined the consequences of Inpp $4 b$ deficiency on $H-R_{a s} s^{V 12} / E 1 A$ mediated MEF transformation. For these experiments we infected early passage Inpp $4 b^{+/+}$and Inpp $4 b^{-/-}$MEF with retrovirus expressing both $H$-Ras ${ }^{V 12}$ and E1A (12SLRC). Upon infection of cells, we observed no difference in the morphology in all $H$-Ras ${ }^{V 12} / E 1 A$ transformed cells of either genotype. Moreover, we observed no difference between the transformed MEF from Inpp $4 b^{+/+}$and Inpp $4 b^{-/}$backgrounds on foci formation in clonogenic assays (Figure 1F) and anchorage independent colonies in soft agar (Figure 1G, 1H). These data suggest that Inpp 4bdeficiency does not lead to spontaneous transformation of MEF and that Inpp $4 b$ expression is dispensable for $H$-Ras ${ }^{V 12} / E 1 A$ mediated MEF transformation. 


\section{Neither loss nor overexpression of INPP4B cooperate with $\mathrm{H}-\mathrm{Ras}^{V 12}$ in $\mathrm{MEF}$ transformation}

To characterize the cooperativity of Inpp $4 b$ deficiency with $H$-Ras ${ }^{V 12}$ overexpression in cellular transformation, early passage Inpp $4 b^{+/+}$and Inpp $4 b^{-/ 2}$ MEF were infected with retroviral particles generated from the pBabe-H-Ras ${ }^{V 12}$-puro vector. Morphologically, both H-Ras ${ }^{V 12}$; Inpp $4 b^{+/+} H$-Ras ${ }^{V 12}$; Inpp $4 b^{-/ 2}$ MEF demonstrated the expected features of oncogene-induced senescence (OIS) including complete growth inhibition (Figure 2A) and large multinucleated senescent-like cells (Figure 2B). Neither H-Ras ${ }^{V 12}$; Inpp $4 b^{+/+}$nor $\mathrm{H}-\mathrm{Ras}^{V 12}$; Inpp $4 b^{-/ 2} \mathrm{MEF}$ were able to form colonies in clonogenic assays (Figure 2C). Similarly, no anchorage-independent colonies were observed in soft agar (Figure 2D). Conversely, positive control MEF infected with $H$-Ras ${ }^{V 12}$ and $E 1 A$ retroviruses generated rapidly proliferating cells (Figure 2A), abundant foci (Figure 2E, top) and numerous anchorage independent colonies (Figure 2E, bottom).
A

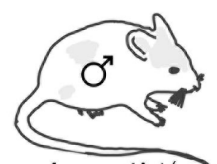

Inpp $4 b^{+/-}$

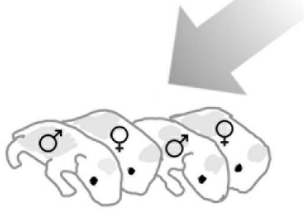

$+/++/-\quad-/-$

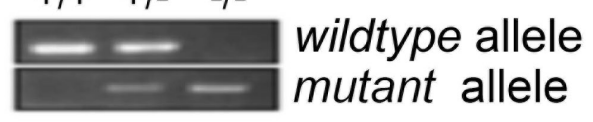

C
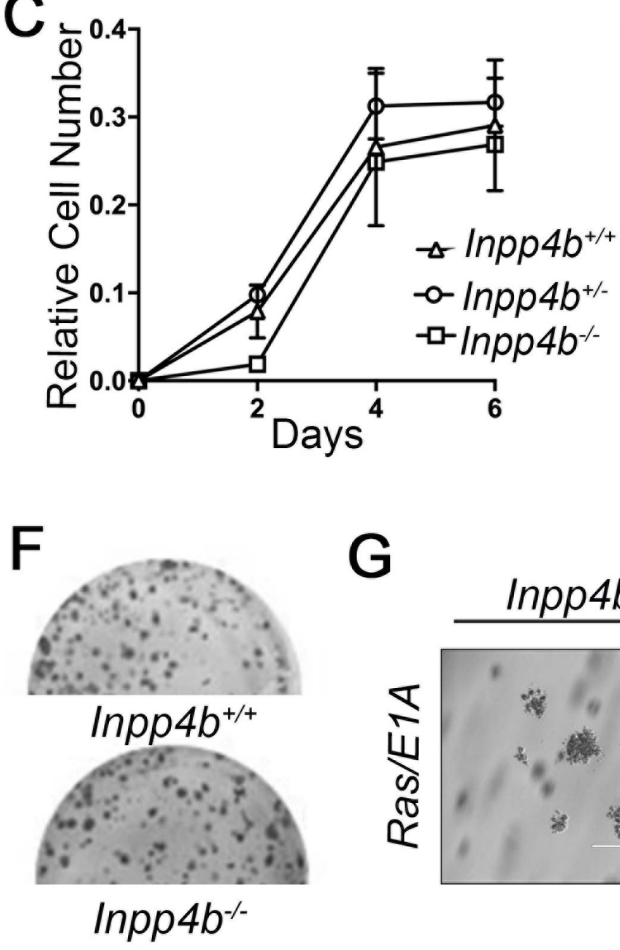
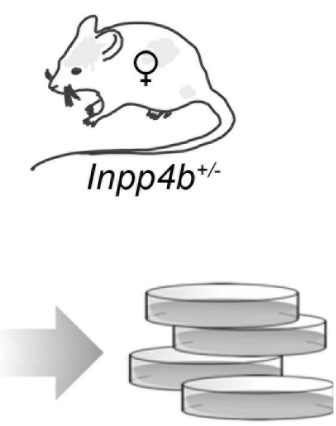

wildtype allele mutant allele

\section{B}
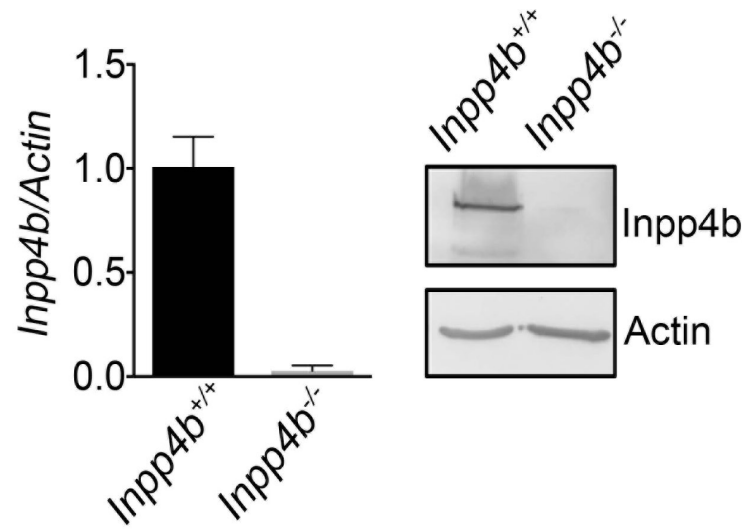

$\mathrm{D}$

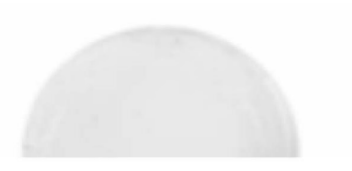

$E$

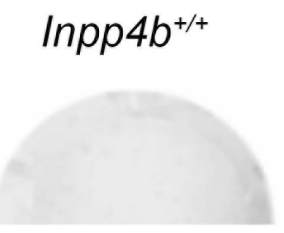

Inpp4 $b^{-/-}$

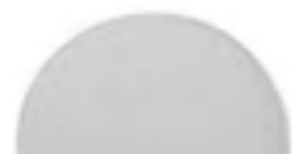

Inpp $4 b^{+/+}$

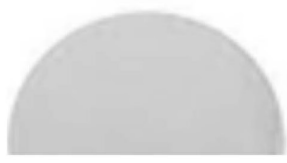

Inpp $4 b^{-/-}$

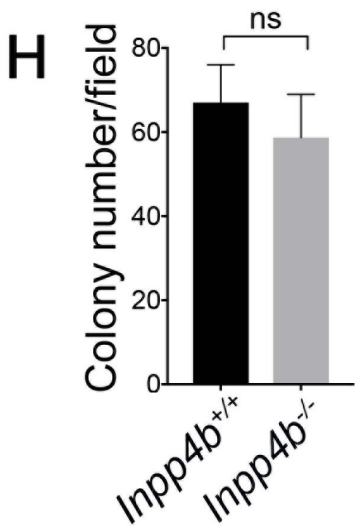

Figure 1: Generation and characterization of primary Inpp $4 b^{+/+}$, Inpp $4 b^{+/}$and $I n p p 4 b^{-/}$MEF. (A) Schematic illustrating breeding strategy for generation of primary MEF and a typical Inpp $4 b$ genotyping PCR result is illustrated. (B) RT-qPCR and Immunoblot demonstrating Inpp $4 b$ expression levels in Inpp $4 b^{+/+}$and Inpp $4 b^{-/}$MEF. (C) Growth curve, (D) colony formation (E) and soft agar assay of primary Inpp $4 b^{+/+}$and Inpp $4 b^{-/}$MEF. (F) Colony formation assay with Inpp $4 b^{+/+}$and Inpp $4 b^{-/}$MEF empty vector and 12SLRC H-Ras ${ }^{V I 2 /}$ E1A infection. (G) Representative soft agar assay of $12 S L R C H-$ Ras $^{V 12} / E 1 A$ infected Inpp $4 b^{+/+}$and Inpp $4 b^{-/-}$MEF. Photos of representative colonies at 20X. (H) Quantitation of quantitation of foci formation assay. 
Next, to examine the potential of $I N P P 4 B$ as an oncogene in MEF, we investigated whether INPP4Boverexpression could cooperate with $H-R_{a s} s^{V 12}$ in cellular transformation. Retrovirus generated from $p W Z L-H-$ Ras $^{V 12}$-hygro vector was combined with either $M S C V$ Puro-IRES-GFP (PIG)-empty or PIG-INPP4B retrovirus to co-infect wild-type MEF followed by selection with hygromycin B and puromycin. Morphologically both $H$-Ras ${ }^{V 12} ; \quad P I G$ or H-Ras V12; PIG-INPP4B infected MEF appeared large and multinucleated (Figure $2 \mathrm{~F}$ ) as expected with $H$-Ras ${ }^{V 12}$ infection. Foci were not observed in clonogenic assays (Figure 2G) and similarly, no anchorage-independent colonies were observed in soft agar assays (Figure 2H). Inpp $4 b^{+/+} \mathrm{MEF}$ infected with $H$-Ras ${ }^{V 12}$ and $E 1 A$ retroviruses which generated abundant foci (Figure 2I, top) and anchorage independent colonies (Figure 2I, bottom) were used as positive controls. Overall, neither deficiency nor overexpression of INPP4B demonstrated cooperativity with $H$-Ras ${ }^{V 12}$-overexpression in cellular transformation.

\section{Neither loss nor overexpression of INPP4B cooperate with $E 1 A$ in $M E F$ transformation}

To investigate whether loss of Inpp $4 b$ is sufficient to cooperate with $E 1 A$ in promoting cellular transformation, early passage Inpp $4 b^{+/+}$and Inpp $4 b^{-/-}$MEF were infected with $p W Z L-E 1 A$-hygro retrovirus and selected with hygromycin B. Immediately after selection, MEF were plated for growth analysis, clonogenic assay and soft agar assays. Inpp $4 b^{+/+}, \operatorname{Inpp} 4 b^{+/}$and Inpp $4 b^{-/}$MEF infected with $E 1 A$ alone were growth inhibited compared to $H$-Ras ${ }^{V 12} ;$ E1A controls (Figure 3A). Morphologically both Inpp $4 b^{+/+}$and Inpp $4 b^{-/}$MEF appeared smaller and more dispersed compared to primary MEF (Figure 3B); clonal outgrowth on plastic observed after 21 days was similarly very minimal in both Inpp $4 b^{+/+}$and Inpp $4 b^{-/-}$MEF (Figure 3C) and no anchorage independent growth colonies formed in soft agar (Figure 3D). Conversely, Inpp 4b $b^{+/+}$ and Inpp $4 b^{-/-}$MEF overexpressing both $H$-Ras ${ }^{V 12}$ and E1A rapidly proliferated in 6-day growth curves (Figure 3A), grew many more foci in the clonogenic assay (Figure 3E, top) and formed large robust colonies in soft agar (Figure 3E, Bottom).

Next, INPP4B overexpression was tested for its ability to cooperate with $E 1 A$ to induce cellular transformation in MEF. For these experiments, wildtype MEF were retrovirally infected with $p W Z L-E 1 A$ hygro vector with either $P I G$ or $P I G-I N P P 4 B$ and selected with hygromycin B and puromycin for 48 hours. Morphologically, E1A; PIG MEF appeared smaller than primary cells (Figure 3F, top) whereas E1A; PIG-INPP $4 B$ MEF appeared larger, more elongated with long spindlelike protrusions and multinucleated (Figure 3F, bottom). No significant differences in foci counts were observed between $E 1 A$; PIG and E1A; PIG-INPP $4 B$ in clonogenic assays (Figure 3G). Anchorage independent growth was not observed in either E1A; PIG and E1A; PIG-INPP4B MEF (Figure $3 \mathrm{H}$ ), but both clones and foci were clearly observed in the control cells infected with $H-$ Ras $^{V 12}$ and $E 1 A$ retroviruses (Figure 3I). Overall, as with $H$-Ras ${ }^{V 12}$ overexpression, neither Inpp $4 b$-deficiency nor INPP $4 B$ overexpression were able to cooperate with $E 1 A$ in cellular transformation.

\section{Inpp $4 b$ deficiency increases colony forming potential in SV4O T-Large MEF}

We next investigated cooperativity of Inpp $4 b$ deficiency with SV4O T-large overexpression. As before, SV40 T-Large retrovirus was used to infect early passage Inpp $4 b^{+/+}$and Inpp $4 b^{-/-}$MEF. Morphologically, no differences were observed between Inpp $4 b^{+/+}$and Inpp $4 b^{-/}$MEF lines (Figure 4A). Immunoblot analysis of SV4O T-Large Inpp $4 b^{+/+}$and Inpp $4 b^{-/-}$demonstrated similar levels of p53 protein and no changes in PTEN expression (Figure 4C). Notably, unlike $H$-Ras ${ }^{V 12}$ and E1A, SV40 T-Large infected Inpp $4 b^{-/-}$MEF demonstrated a significant $(P=0.025)$ increase in foci formation (Figure 4C) and a significant $(P=0.0011)$ increase in anchorage independent colonies in soft agar (Figure 4D). These findings demonstrate cooperativity between SV40 T-Large overexpression and Inpp $4 b$ deficiency in MEF and suggest that Inpp $4 b$ may function as a tumour suppressor in the context of SV40 T-Large transduction.

Given this increase in SV40 T-Large transformation potential observed in Inpp $4 b^{-/} \mathrm{MEF}$, we reasoned that INPP4B overexpression would limit anchorage independent growth of SV40 T-Large MEF. To investigate this, early passage $S V 40$ T-Large $M E F$ were transduced with $P I G$ and $P I G-I N P P 4 B$ retrovirus (Figure $5 \mathrm{~A}$ ). Although there were no gross morphological differences between $P I G$ and $P I G-I N P P 4 B$ transduced SV40 $T$-Large MEF (Figure 5B), we did observe that INPP4B overexpression in MEF SV40 T-Large MEF displayed a significant reduction $(P=0.0018)$ in colony number as compared to control (Figure 5C). Immunoblot analysis of SV40 T-Large Inpp $4 b^{+/+}$and Inpp $4 b^{-/}$demonstrated no changes Pten protein levels upon INPP4B overexpression (Figure 5A).

\section{Inpp $4 b$ modulates EGF stimulated PI3K signaling in SV40 T-Large MEF}

To explore the relationship of Inpp $4 b$ deficiency on PI3K signaling in MEF, low-passage $\operatorname{Inpp} 4 b^{+/+}$and Inpp $4 b^{-/-}$SV40T-Large MEF were serum starved overnight and stimulated with epidermal growth factor (EGF). We consistently observed that Inpp $4 b^{-/-} \mathrm{MEF}$ achieved higher peak levels of $\mathrm{pSer}^{473}$-Akt activation at 5-10 minutes compared to timepoints in Inpp $4 b^{+/+} \mathrm{MEF}$. Inpp $4 b^{-/-} \mathrm{MEF}$ maintained prolonged peak levels of $\mathrm{pSer}^{473}$-Akt beyond 
10 minutes of EGF and remained higher than $\operatorname{Inpp} 4 b^{+/+}$ $\mathrm{MEF}$ up to $30 \mathrm{~min}$ (Figure 6A). Conversely, INPP4B overexpression in SV40 T-Large MEF led to markedly decreased levels of $\mathrm{pSer}^{473}$-Akt after EGF stimulation. This decrease was observed at the peak pSer ${ }^{473}$-Akt concentrations of 5 and 10 minutes (Figure 6B). Together these results indicate that INPP4B regulates Akt activation dynamics in stimulated SV40T-Large MEF.

\section{DISCUSSION}

Altered levels of INPP4B expression have been linked with cancer progression in various different human tumour types [42]. Previous works have demonstrated that INPP $4 B$ knockdown induced anchorage-independent cell growth, increased invasion and migration, and augmented Akt activation in immortalized HMECs $[8,9]$. In contrast,

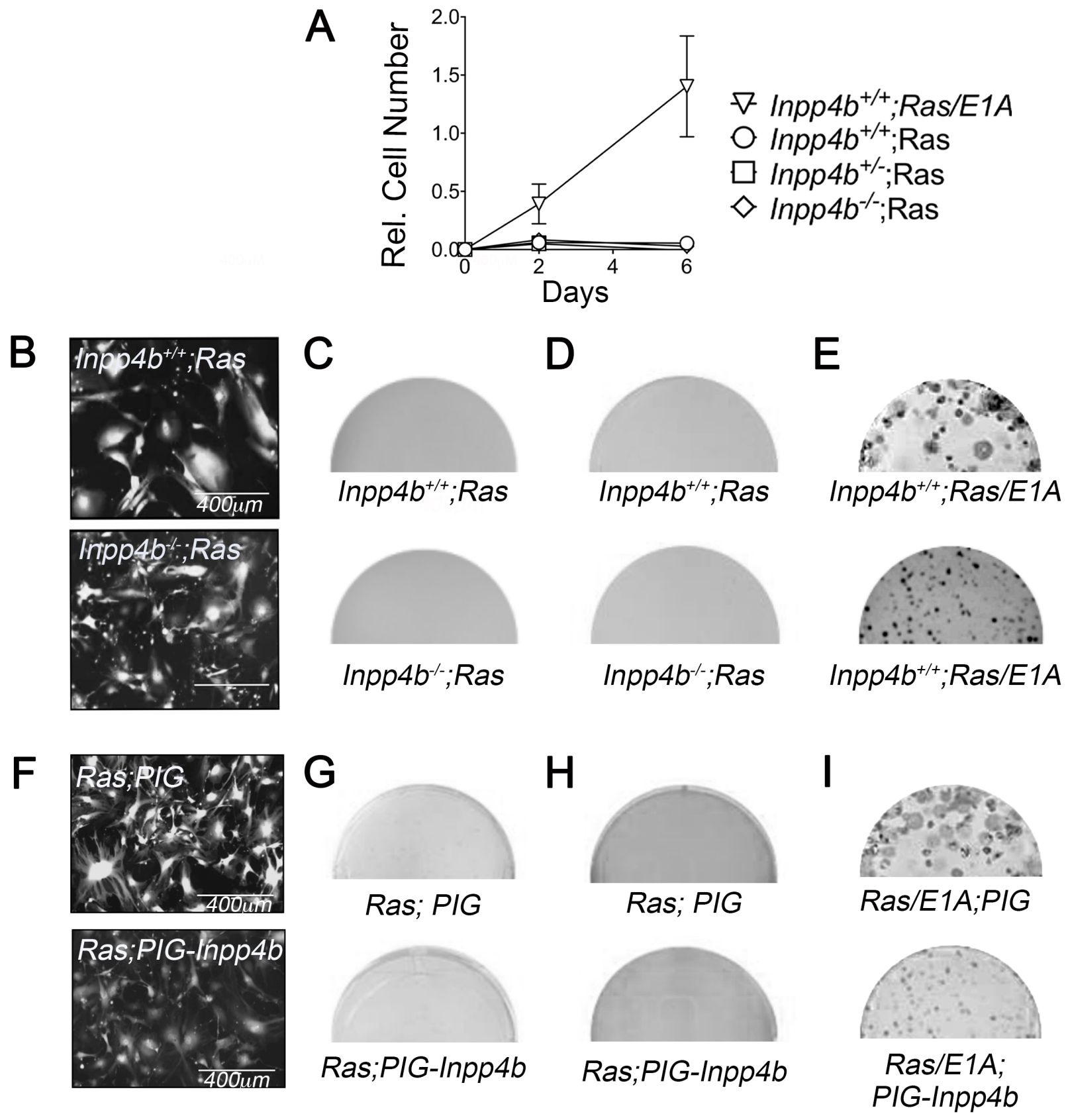

Figure 2: Inpp4b loss or overexpression do not cooperate with $\boldsymbol{H}$-Ras ${ }^{V 12}$ in MEF transformation. (A) 6-day growth curve of Inpp $4 b^{+/+}$, Inpp $4 b^{+/-}$and Inpp $4 b^{-/-}$MEF after HRas ${ }^{V 12}$ infection. 12SLRC H-Ras ${ }^{V 12} / E 1 A$ infected Inpp $4 b^{+/+}$MEF used as control. (B) Morphology of eGFP-expressing Inpp $4 b^{+/+}$and Inpp $4 b^{-/-}$MEF after $H$-Ras ${ }^{V 12}$ infection. (C) Colony formation and (D) Soft agar assay of primary Inpp $4 b^{+/+}$and Inpp $4 b^{-/-}$MEF after $H$-Ras $S^{V 12}$ infection. (E) $12 S L R C H$-Ras ${ }^{V 12} / E 1 A$ infected colony assay (top) and soft agar (bottom) controls. Full wells are depicted. (F) Morphology of eGFP-expressing Inpp $4 b^{+/+}$MEF after $H$-Ras ${ }^{V I 2}$ and PIG or PIG-Inpp $4 b$ infection. (G) Colony formation and; (H) Soft agar assay of primary Inpp $4 b^{+/+}$MEF after H-Ras ${ }^{V 12}$ and PIG or PIG-Inpp $4 b$ infection (I) $12 S L R C H$-Ras ${ }^{V 12}$ / $E 1 A$ and $P I G$ or PIG-Inpp $4 b$ infected colony assay (top) and soft agar (bottom) controls. 
other reports show that $I N P P 4 B$ overexpression enhanced proliferation and promotes anchorage-independent growth of HEMn-MP melanocytes and FHC normal colon epithelial cells [34, 38]. Herein, we present results which indicate that deficiency of Inpp $4 b$ in MEF can cooperate with very specific oncogenic alterations to induce cellular transformation. In our study, we observed that neither heterozygosity nor deficiency of Inpp $4 b$ were sufficient to alter growth characteristics of MEF on their own (Figure
1C). Spontaneous immortalization of MEF was also not observed in colony formation assays (Figure 1D, 1E). Similarity, Inpp $4 b$ deficiency was inconsequential for $H$-Ras ${ }^{V 12} / E 1 A$ induced cellular transformation of MEF (Figure 1F, 1G). Inpp $4 b$ deficiency did not inhibit $H$-Ras ${ }^{V 12}$ / E1A-induced cellular transformation as both Inpp $4 b^{-/-}$and Inpp $4 b^{+/+}$MEF displayed long-term growth potential consistent with immortalization and in an anchorage independent manner in the soft agar assay (Figure 1G, 1H).

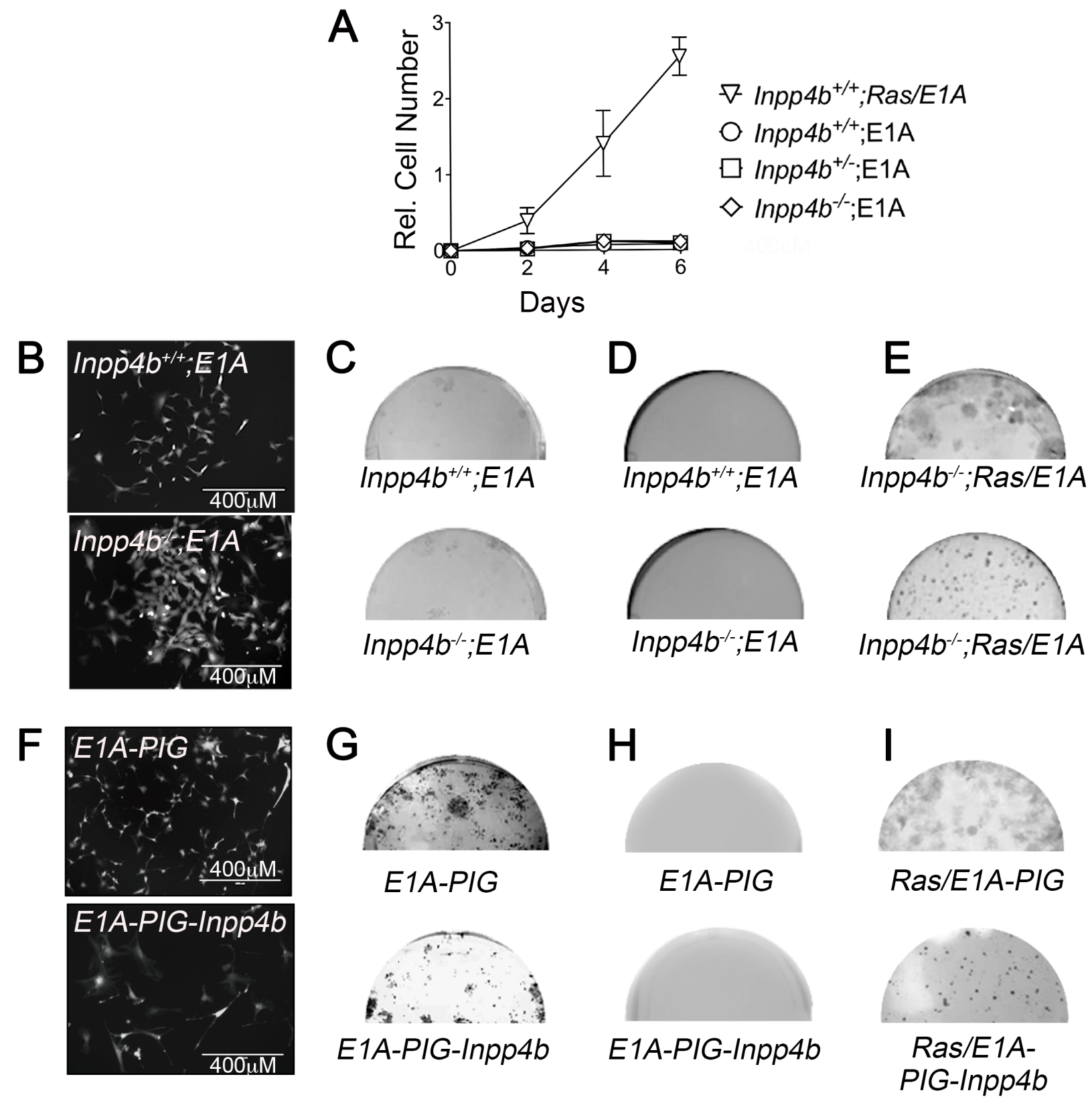

Figure 3: Inpp4b loss or overexpression do not cooperate with $E 1 A$ in MEF. (A) 6-day growth curve of MEF after $E 1 A$ infection. 12SLRC $H$-Ras ${ }^{V 12} / E 1 A$ infected Inpp $4 b^{+/+}$MEF used as control. (B) Morphology of eGFP-expressing Inpp $4 b^{+/+}$and Inpp $4 b^{-/-}$ MEF after E1A infection. (C) Colony formation and; (D) Soft agar assay of primary Inpp $4 b^{+/+}$and Inpp $4 b^{-/-}$MEF after E1A infection and (E) 12 SLRC H-Ras ${ }^{V 12} / E 1 A$ infected colony assay (left) and soft agar (right) controls. Half wells are depicted. (F) Morphology of eGFPexpressing Inpp $4 b^{+/+} \mathrm{MEF}$ after $E 1 A$ and $P I G$ or PIG-Inpp $4 b$ infection. (G) Colony formation and; (H) Soft agar assay of primary Inpp $4 b^{+/+}$ MEF after E1A and PIG or PIG-Inpp $4 b$ infection (I) 12 SLRC H-Ras ${ }^{V 12} / E 1 A$ and PIG or PIG-Inpp $4 b$ infected colony assay (left) and soft agar (right) controls. 
A

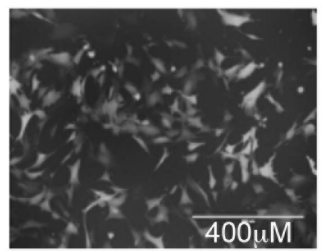

Inpp $4 b^{+/+} ;$SV40

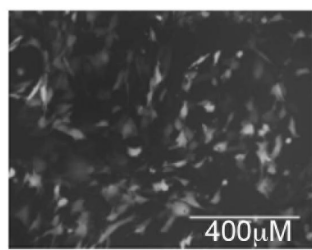

Inpp4b-;SV40
B

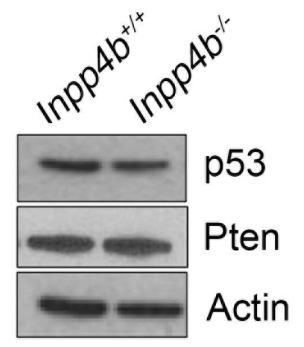

C

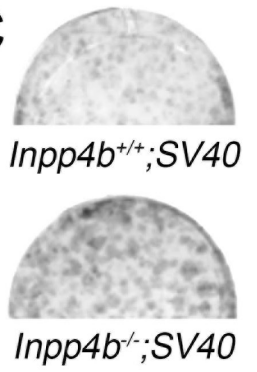

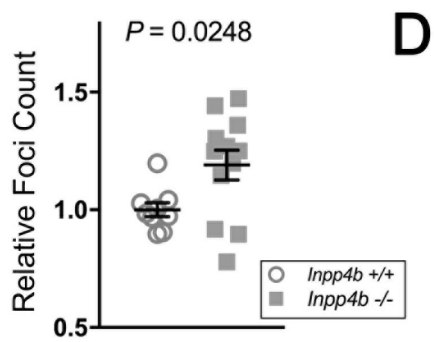

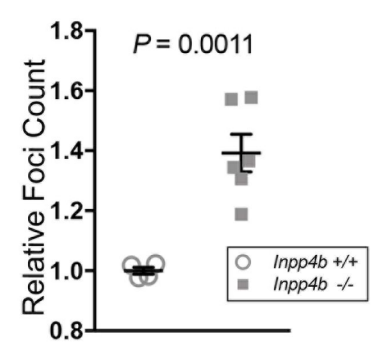

$\operatorname{lnpp} 4 b^{-/} ; S V 40$

Figure 4: Inpp4b deficiency increases colony forming potential of SV40 T-Large in MEF. (A) Morphology of eGFPexpressing Inpp $4 b^{+/+}$and Inpp $4 b^{-/-}$MEF after SV40 T-Large infection. (B) Immunoblot of Inpp $4 b^{+/+}$and Inpp $4 b^{-/}$SV40 T-Large MEF. (C) Representative clonogenic and (D) Soft agar assay plates with quantitation below. $P$-values were determined using the Student's $t$-test.

A

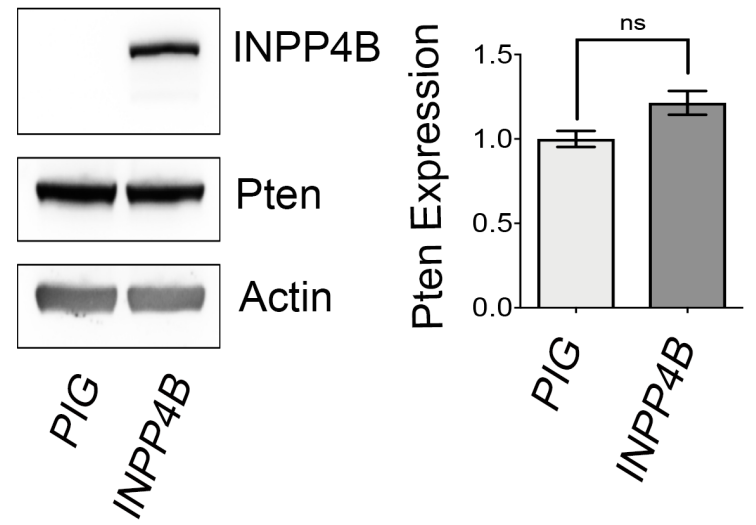

B

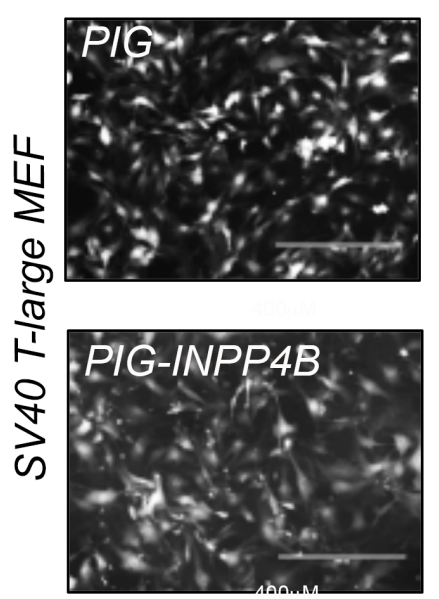

C

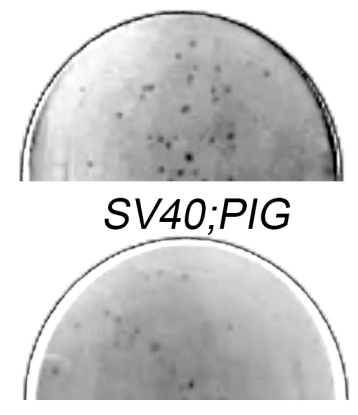

SV40; PIG-INPP4B

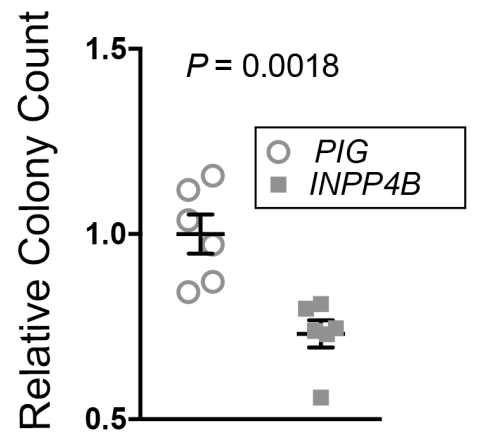

Figure 5: Inpp4b overexpression decreases transformation potential in SV40 T-Large MEF. (A) Immunoblot measuring INPP4B overexpression and Pten levels in SV40T-Large MEF $(n=5)$. (B) Morphology of eGFP-expressing Inpp 4b $b^{+/+}$SV40T-Large MEF with $P I G$ or PIG-Inpp $4 b$ transduction. (C) Representative soft agar assay plates and quantitation of Inpp $4 b^{+/+}$SV $40 T-L a r g e$ MEF with $P I G$ or PIG-Inpp $4 b$ colonies. $P$-values were determined using the Student's $t$-test. 
When co-expressed in MEF, $H$-Ras ${ }^{V 12}$ and E1A potently induce cellular transformation due to the strong proliferative signaling through $H$-Ras ${ }^{V 12}$ concomitant with inhibition of the $R b$ tumour suppressor pathway by $E 1 A$ which bypasses Ras-induced senescence [44, 45]. Inpp $4 b$ deficiency did not cooperate with $H$-Ras ${ }^{V 12}$ nor E1A oncogene overexpression to promote MEF transformation suggesting that Inpp $4 b$ may not play a role in $E 1 A$ or Ras signaling pathways in MEF (Figures 2-3).

However, Inpp $4 b$ deficiency did promote $S V 40$ T-Large mediated transformation of MEF, as demonstrated by an increase in anchorage independent growth and colony formation as compared to controls (Figure 4C-4D). Increased SV4O T-Large mediated cellular transformation was associated with elevated Akt activation as demonstrated by elevated $\mathrm{pSer}^{473}$-Akt after stimulation of starved MEF with EGF (Figure 6). Together, these findings are consistent with studies by Westbrook et al. [9] and Gewinner et al. [8] which demonstrated that shRNA knock-down of INPP $4 B$ in HMEC cells immortalized with SV4O T-Large and hTERT promoted cellular transformation. In addition, that Inpp $4 a^{-1-}$ MEF also displayed elevated pAkt levels compared to wild type after SV4O T-Large immortalization [46] support the notion that 4-phosphatase function is tumour suppressive in part through regulation of Akt signaling. Other mechanisms which have been linked to INPP4B loss include loss of ATM and ATR, both upstream regulators of the p53 pathway $[22,47]$ and INPP4B was reported to downregulate PTEN protein through its protein phosphatase activity [34]. Our efforts in this study demonstrated that p53 and Pten expression levels were unchanged between Inpp $4 b^{+/+}$ and Inpp $4 b^{-/}$SV40 T-Large MEF (Figure 4B) indicating that these mechanisms may not be associated with the phenotypes we observed in MEF.
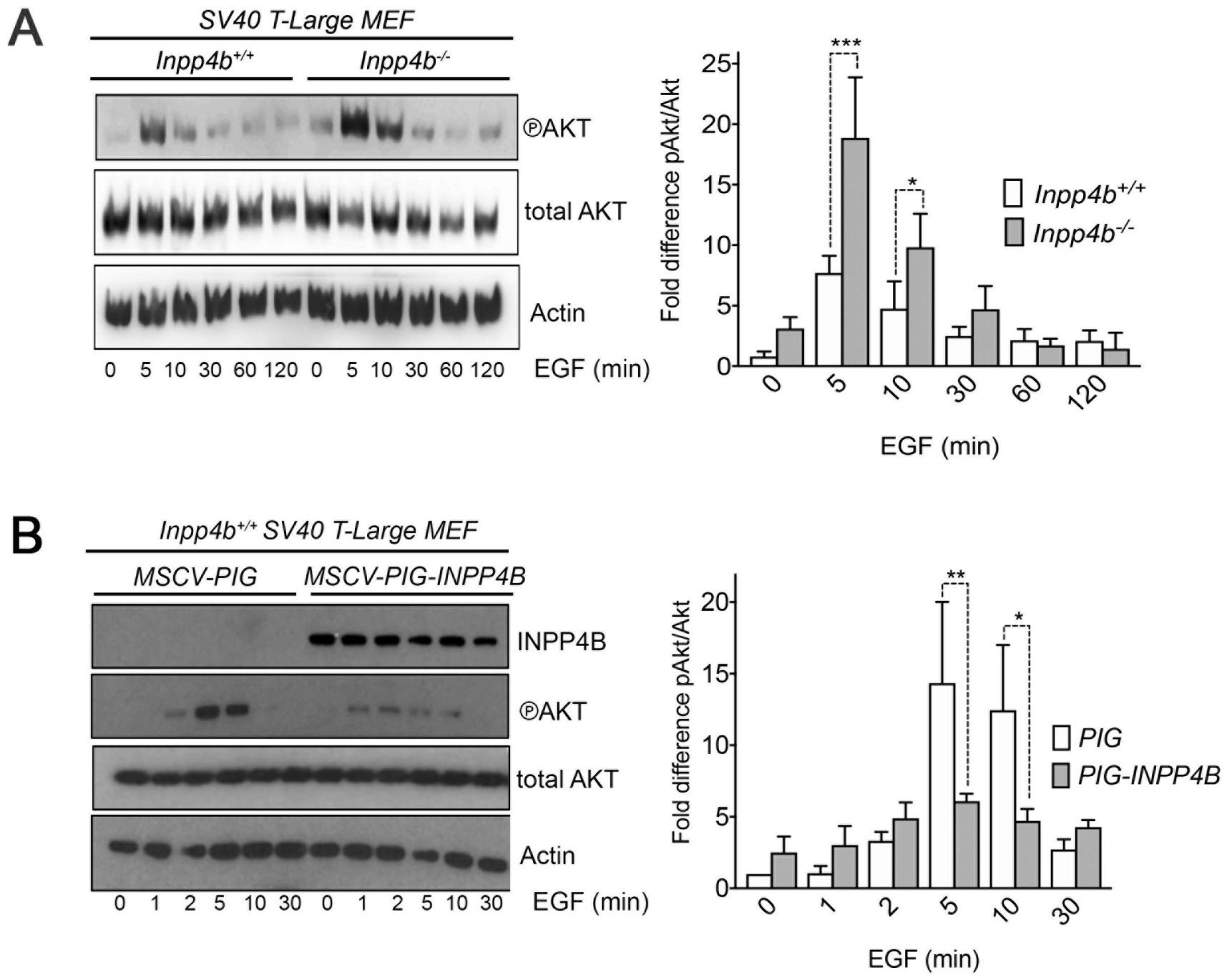

Figure 6: Inpp4b modulates EGF stimulated Akt activation in SV40 T-Large MEF. SV40T-Large MEF were serum starved and stimulated with $100 \mathrm{ng} / \mathrm{mL}$ of EGF and immunoblotted with pSer ${ }^{473}$-Akt. (A) Immunoblot of pSer ${ }^{473}$-Akt of SV40 T-Large Inpp $4 b^{+/+}$and Inpp $4 b^{-/-} \mathrm{MEF}$ with quantitation of $\mathrm{pSer}^{473}$-Akt activation status $(n=4)(\mathbf{B})$ Immunoblot of $\mathrm{pSer}^{473}$-Akt SV40T-Large; PIG or SV40T-Large; $P I G-I N P P 4 B$ MEF with quantitation plot of $\mathrm{pSer}^{473}$-Akt activation status $(n=3)$. $P$-values were determined using ANOVA. ${ }^{*} P<0.05$, ${ }^{* *} P<0.01,{ }^{* * *} P<0.005$. 
Conversely, emerging evidence suggests that INPP4B overexpression may also promote tumourigenesis and cancer progression [32-36]. Thus, we tested whether INPP $4 B$ overexpression in MEF drives or cooperates with other transforming oncogenes in cellular transformation. We observed that INPP $4 B$ overexpression was unable to promote transformation in combination with $H-R_{a s}{ }^{V 12}$, E1A nor SV40 T-Large MEF. In fact, overexpression of $I N P P 4 B$ in SV4O T-Large MEF significantly decreased cellular transformation and concomitantly decreased $\mathrm{pSer}^{473}$-Akt levels (Figures 5, 6). These findings were reminiscent of those reported by Fedele et al. [10] in serum starved and EGF stimulated MCF7 at similar time points, where peak pAkt levels were lower after INPP $4 B$ knockdown, but at 30 minutes INPP4B overexpressing cells displayed slightly increased pAkt levels compared to the control [10]. Taken together, these findings highlight a tumour suppressive role for Inpp $4 b$ in the context of SV40 T-Large that coincides with elevated Akt activation and suggest that a functional alteration conferred by $S V 40$ T-Large transduction cooperates with Inpp $4 b$ loss to promote cellular transformation in vitro.

In summary, our study aimed to address the role for Inpp $4 b$ in cellular transformation. Given the numerous contrasting models for INPP $4 B$ function in cancer, we investigated both deficiency and overexpression to elucidate predominant tumour suppressor or oncogenic roles, respectively in MEF. With respect to $\mathrm{MEF}$ transformation, we observed that INPP $4 B$ overexpression did not promote oncogenesis when combined $H-R_{a s}{ }^{V 12}$, $E 1 A$ or SV40-T-large transduction. Although Inpp $4 b$ deficiency did not cooperate with overexpression $H$-Ras ${ }^{V 12}$, nor $E 1 A$, we did observe that Inpp $4 b$ deficiency can increase the transformation potential of SV40-T-large transduction suggesting that Inpp $4 b$ may function in a tumour suppressive manner in this context, at least in part through its control of Akt activation. This suggests that an event specifically associated with suppressing SV4OT-large transformation is relieved by Inpp $4 b$ deficiency. Further investigation is required to elucidate the specific mechanisms at play.

\section{MATERIALS AND METHODS}

\section{MEF preparation and culture conditions}

Timed breedings were performed with C57BL/6J Inpp $4 b^{+/}$pairs and embryos were dissected from euthanized mothers at 13.5 days post-coitum. The skin fibroblasts were separated from the head and viscera and incubated in $2 \mathrm{~mL}$ of $0.25 \%$ trypsin for 30 minutes. The solution was then mixed vigorously by pipetting, followed by the addition of another $2 \mathrm{~mL}$ of trypsin and incubated at $37^{\circ} \mathrm{C}$ and $5 \% \mathrm{CO}_{2}$. After 30 minutes, the trypsin was neutralized by adding $1 \mathrm{~mL}$ of fetal bovine serum (FBS), and re-suspended and grown in complete growth media (Dulbecco's Modified Eagle Medium (DMEM) supplemented with $10 \%$ FBS and $1 \%$ penicillin/ streptomycin) for 12-16 hours. Once the MEF had grown to confluency, the cells were frozen down and designated as Passage 1. Primary MEF were passaged every 3 days to not exceed $1.5 \times 10^{6}$ cells per $10 \mathrm{~cm}$ dish. MEF were considered primary from Passage 1-Passage 4. All experiments were performed with primary MEF unless otherwise indicated.

\section{Genotyping}

DNA was extracted by lysing the heads of the mouse embryos in DNA extraction buffer (1M Tris ( $\mathrm{pH} 8$ ), 20\% SDS, 0.5M EDTA, $5 \mathrm{M} \mathrm{NaCl}$ made up in water) containing $10 \%$ proteinase $\mathrm{K}$ at $55^{\circ} \mathrm{C}$ shaking for approximately 16 hours. An equal volume of $100 \%$ ethanol was added and centrifuged at $21.9 \times \mathrm{g}$ for 10 minutes. The supernatant was discarded, and the DNA pellet was washed with $70 \%$ ethanol, dried completely, and re-suspended in 50 $\mathrm{uL}$ of nuclease-free water. PCR was performed using $2 \mathrm{X}$

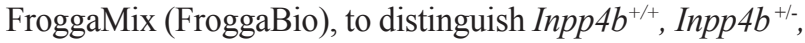
and Inpp $4 b^{-/ .}$. Genotyping primer pairs: wild type forward: 5' GCTTCTGATAAAACATGGG 3', wild type reverse: 5' TGGGCACATTTATAAGCCTTC 3', mutant forward: 5' GCTTCTGATAAAACATGGG 3', and mutant reverse: 5' TGTTTTAAAAGCCTTGCTTGCTAAGTGTC 3'.

\section{Retroviral constructs}

The following plasmids were purchased from AddGene: $p$ WZL hygro H-Ras ${ }^{V 12}$ (\#18749), pBabe-puro H-Ras ${ }^{V 12}$ (\#1768), pWZL hygro 12S E1A(\#18748), and MSCV-puro-IRES-GFP (\#21654). pWZL hygro SV40Tlarge was a kind gift from Pier Paolo Pandolfi, and 12SLRC H-Ras ${ }^{V 12} / E 1 A$ was a kind gift from Marisol Soengas. The $M S C V$-PIG-FLAG-Inpp $4 b$ was cloned by adding FLAG-Inpp $4 b$ to the MSCV-puro-IRES-GFP plasmid through Gibson Assembly (NEB).

\section{Retroviral transduction}

For transfection of retroviral constructs, $3.0 \times 10^{6}$ $293 \mathrm{~T}$ cells were seeded on a $10 \mathrm{~cm}$ dish 24 hours prior to calcium phosphate transfection. Media was changed 3-4 hours prior to transfection. For each $10 \mathrm{~cm}$ dish, $10 \mathrm{ug}$ of retroviral plasmid and 5 ug of retroviral packaging vector, pCL-Eco, were combined with $2 \mathrm{M} \mathrm{CaCl}_{2}$ and made up to a final volume of $300 \mathrm{uL}$ with sterile water. This DNA/ $\mathrm{CaCl}_{2}$ mixture was vortexed while $300 \mathrm{uL}$ of $2 \mathrm{X}$ HEPESBuffered saline (HBS; $140 \mathrm{mM} \mathrm{NaCl}, 1.5 \mathrm{mM} \mathrm{Na} 2 \mathrm{HPO} 4$ ) was slowly added to mixture. $600 \mathrm{ul}$ of DNA/ $\mathrm{CaCl}_{2} / \mathrm{HBS}$ mixture was gently pipetted onto $293 \mathrm{~T}$ cells. Media was changed 24 hours after transfection and supernatants was collected at 48- and 72-hours post-infection. MEF were seeded at $8.0 \times 10^{5}$ cells $/ 10 \mathrm{~cm}$ dish 24 hours prior to 
infection. Fresh virus-rich media was collected and filtered using a 0.45 -micron filter and added to respective plate along with $8 \mu \mathrm{g} / \mathrm{ml}$ protamine sulfate. Infections were repeated every 8 hours to increase infection efficiency. PWZL-hygro and PWZL-H-Ras ${ }^{V 12}$-hygro were used as negative controls, and coinfection with $P W Z L-E 1 A$-hygro and $p B A B E-H$-Ras ${ }^{V 12}$-puro were used as positive controls. Wild Type MEF cells were transfected with MSCV-

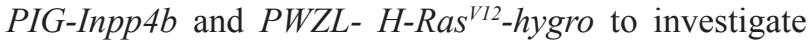
INPP4B overexpression in cooperation with $H$-Ras ${ }^{V 12}$ overexpression. Inpp $4 b^{-/-} \mathrm{MEF}$ cells were transfected with pBABE-H-Ras ${ }^{V 12}$-puro to investigate the effects of Inpp $4 b$ deficiency in cooperation with $H$-Ras ${ }^{V 12}$ overexpression on cellular transformation. Cells were selected for 4 days with hygromycin B at $75 \mu \mathrm{g} / \mathrm{ml}$ or 2 days of puromycin at $2 \mu \mathrm{g} / \mathrm{ml}$ selection, then cells recovered for 24 hours before plating for experiments. MEF infected with both puromycin and hygromycin B resistance plasmids were first selected for 4 days with hygromycin B at $75 \mathrm{ug} / \mathrm{mL}$, allowed to recover for 24 hours and subsequently selected with $2 \mu \mathrm{g} / \mathrm{ml}$ puromycin; The cells were then allowed to recover for 24-48 hours before plating experiments.

\section{Growth assays}

MEF were seeded at a density of $2.5 \times 10^{4}$ cells per well in a 12-well plate for a 6-day growth curve. At each time point, cells were fixed with $10 \%$ formalin for 10 minutes and stored in phosphate-buffered saline (PBS) at $4^{\circ} \mathrm{C}$. Once all time points were collected, cells were stained with $0.1 \%$ crystal violet, $20 \%$ methanol solution, then washed with water and dried for at least 4 hours. The crystal violet stain was solubilized by $10 \%$ acetic acid for 20 minutes and the absorbance was measured at $590 \mathrm{~nm}$ with Spectramax M3.

\section{Clonogenic assays}

MEF were plated at 1000 cells per well in a 6-well plate and allowed to grow for 10-20 days without media change. Cells were then washed with PBS, fixed with $10 \%$ formalin and stained with $0.1 \%$ crystal violet, $20 \%$ methanol solution, washed with water and allowed to dry. Colonies were imaged and counted using Image J. Cell counts were normalized to the control group.

\section{Anchorage independence assays}

$200 \mathrm{~mL}$ of $6 \%$ Noble Agarose in sterile water was heated until liquified and brought to $42^{\circ} \mathrm{C}$. Soft agar plates were prepared by mixing $2 \mathrm{~mL}$ of melted $6 \%$ Noble Agarose in MilliQ water in $18 \mathrm{ml}$ of complete DMEM. 3 $\mathrm{mL}$ of $0.06 \%$ Noble Agar was plated per well of a 6 well dish and placed at $4^{\circ} \mathrm{C}$ to solidify. 1 hour prior to plating the dish was preheated in a $37^{\circ} \mathrm{C}$ cell incubator. 20,000 infected MEF were placed in $7.2 \mathrm{ul}$ of media at $37^{\circ} \mathrm{C}$ then mixed with $0.8 \mathrm{ml}$ of $42^{\circ} \mathrm{C}, 3 \%$ Noble Agarose in MilliQ water to obtain a final concentration of 5000 cells per well in triplicate of a 6 well dish in $0.3 \%$ Agar in DMEM. Colonies were stained using $0.05 \%$ crystal violet in $40 \%$ methanol. Colonies were counted using OpenCFU colony counting software (http://opencfu.sourceforge.net).

\section{qPCR}

RNA was isolated using the Qiagen RNeasy Mini Kit, and subsequently treated with DNase. Reverse transcription was performed using the SuperScript IV VILO Master Mix (Invitrogen, 11766050). TaqMan Fast Advanced Master Mix (appliedbiosystems, 4444557). TaqMan probes for Inpp4b (Mm01247230_m1) and actin (Mm02619580_g1) were purchased from Thermo Fisher Scientific. All of the above conducted according to manufacturers' instructions.

\section{Akt signaling assay}

Passage 3-5 SV40 T-Large MEFs were seeded at 200000 cells per well in 6 wells of a 6 well dish. After the MEF adhered to the bottom of the dish (4-6 hours after plating) the cells were washed twice with serum free DMEM then plated in starvation media (DMEM + $0.01 \%$ FBS). 16 hours later each well was allocated to the indicated time point (minutes). $100 \mathrm{ng} / \mathrm{mL}$ EGF was used to activate PI3K signaling. Activation was terminated at the indicated time points with ice cold PBS, followed by drying of wells, and subsequently flash frozen with liquid nitrogen and placed at $-80^{\circ} \mathrm{C}$ prior to immunoblot.

\section{Western blots}

Immunoblots were performed using standard conditions as previously published [32]. The following antibodies were used in this study. Anti-phospho-Ser ${ }^{473}$ Akt (NEB 14543); anti-pan Akt (NEB 29020); anti- $\beta$ Actin (NEB 4967); anti-FLAG (Abgent AP1013a-ev). Anti-INPP4B antibody detecting murine Inpp4b was a kind gift from Jean Vacher [30].

\section{Statistics}

To compare means of 2 groups $p$-values were calculated using unpaired two-tailed Student's $t$-test. For colony counts of the clonogenic assay and soft agar assay two-way parametric analysis of variance (ANOVA) was used to determine the significance value. A $P$-value $<0.05$ was considered significant.

\section{Abbreviations}

AML: Acute myeloid leukemia; E1A: Adenovirus early region 1A; EGF: Epidermal growth factor; 
H-Ras: Harvey rat sarcoma viral oncogene homolog; HMEC: Human mammary epithelial cells; INPP4B: Inositol Polyphosphate 4-Phosphatase, Type II; MEF: Mouse embryonic fibroblast; PIG: MSCV-Puro-IRESGFP; OIS: Oncogene-induced senescence; PtdIns: Phosphatidylinositol; pAKT: Phosphorylated Akt; Ras: Rat Sarcoma; SGK-3: Serum/Glucocorticoid Regulated Kinase Family Member 3; SV40: Simian Vacuolating Virus 40.

\section{Author contributions}

EEM and LS conceived and designed the study. EEM performed the bulk of experiments with assistance from $\mathrm{KC}$ and BS. JV contributed critical reagents. EEM and LS wrote the manuscript. All authors critically reviewed the manuscript and approved the final draft for submission.

\section{ACKNOWLEDGMENTS}

We sincerely thank Dr. Lina Penn and Dr. Mark Minden for reagents and invaluable advice, and all members of the Salmena lab for critical discussions. We also thank Bell Wu and Aobo He for experimental assistance.

\section{CONFLICTS OF INTEREST}

The authors declare no conflicts of interest.

\section{FUNDING}

LS is the recipient of a Tier II Canada Research Chair. EMM is the recipient of a student incentive award from the Centre for Collaborative Drug Research. This work is funded in part by awards from CIHR (123343) to JV; and NSERC (RGPIN-2015-03984) and CIHR (201604PJT) to LS.

\section{REFERENCES}

1. Whitman M, Downes CP, Keeler M, Keller T, Cantley L. Type I phosphatidylinositol kinase makes a novel inositol phospholipid, phosphatidylinositol-3-phosphate. Nature. 1988; 332:644-646. https://doi.org/10.1038/332644a0. [PubMed]

2. Auger KR, Serunian LA, Soltoff SP, Libby P, Cantley LC. PDGF-dependent tyrosine phosphorylation stimulates production of novel polyphosphoinositides in intact cells. Cell. 1989; 57:167-175. https://doi.org/10.1016/00928674(89)90182-7. [PubMed]

3. Manning BD, Toker A. AKT/PKB signaling: navigating the network. Cell. 2017; 169:381-405. https://doi. org/10.1016/j.cell.2017.04.001. [PubMed]

4. Agoulnik IU, Hodgson MC, Bowden WA, Ittmann MM. INPP4B: the new kid on the PI3K block. Oncotarget.
2011; 2:321-328. https://doi.org/10.18632/oncotarget.260. [PubMed]

5. Scheid MP, Huber M, Damen JE, Hughes M, Kang V, Neilsen P, Prestwich GD, Krystal G, Duronio V. Phosphatidylinositol $(3,4,5) \mathrm{P} 3$ is essential but not sufficient for protein kinase $\mathrm{B}$ (PKB) activation; phosphatidylinositol $(3,4) \mathrm{P} 2$ is required for PKB phosphorylation at Ser-473: studies using cells from SH2-containing inositol-5-phosphatase knockout mice. J Biol Chem. 2002; 277:9027-9035. https://doi.org/10.1074/jbc. M106755200. [PubMed]

6. Frech M, Andjelkovic M, Ingley E, Reddy KK, Falck JR, Hemmings BA. High affinity binding of inositol phosphates and phosphoinositides to the pleckstrin homology domain of RAC/protein kinase B and their influence on kinase activity. J Biol Chem. 1997; 272:8474-8481. https://doi. org/10.1074/jbc.272.13.8474. [PubMed]

7. Franke TF, Kaplan DR, Cantley LC, Toker A. Direct regulation of the Akt proto-oncogene product by phosphatidylinositol-3,4-bisphosphate. Science. 1997; 275:665-668. https://doi.org/10.1126/science.275.5300.665. [PubMed]

8. Gewinner C, Wang ZC, Richardson A, Teruya-Feldstein J, Etemadmoghadam D, Bowtell D, Barretina J, Lin WM, Rameh L, Salmena L, Pandolfi PP, Cantley LC. Evidence that inositol polyphosphate 4-phosphatase type II is a tumor suppressor that inhibits PI3K signaling. Cancer Cell. 2009; 16:115-125. https://doi.org/10.1016/j.ccr.2009.06.006. [PubMed]

9. Westbrook TF, Martin ES, Schlabach MR, Leng Y, Liang AC, Feng B, Zhao JJ, Roberts TM, Mandel G, Hannon GJ, Depinho RA, Chin L, Elledge SJ. A genetic screen for candidate tumor suppressors identifies REST. Cell. 2005; 121:837-848. https://doi.org/10.1016/j.cell.2005.03.033. [PubMed]

10. Fedele CG, Ooms LM, Ho M, Vieusseux J, O'Toole SA, Millar EK, Lopez-Knowles E, Sriratana A, Gurung R, Baglietto L, Giles GG, Bailey CG, Rasko JE, et al. Inositol polyphosphate 4-phosphatase II regulates PI3K/Akt signaling and is lost in human basal-like breast cancers. Proc Natl Acad Sci U S A. 2010; 107:22231-22236. https:// doi.org/10.1073/pnas.1015245107. [PubMed]

11. Cancer Genome Atlas Network. Comprehensive molecular portraits of human breast tumours. Nature. 2012; 490:61-70. https://doi.org/10.1038/nature11412. [PubMed]

12. Hodgson MC, Shao L, Frolov A, Li R, Peterson LE, Ayala G, Ittmann MM, Weigel NL, Agoulnik IU. Decreased expression and androgen regulation of the tumor suppressor gene INPP4B in prostate cancer. Cancer Res. 2011; 71:572-582. https://doi.org/10.1158/0008-5472. CAN-10-2314. [PubMed]

13. Hodgson MC, Deryugina EI, Suarez E, Lopez SM, Lin D, Xue H, Gorlov IP, Wang Y, Agoulnik IU. INPP4B suppresses prostate cancer cell invasion. Cell Commun Signal. 2014; 12:61. https://doi.org/10.1186/s12964-0140061-y. [PubMed] 
14. Cancer Genome Atlas Research Network, Ley TJ, Miller C, Ding L, Raphael BJ, Mungall AJ, Robertson A, Hoadley K, Triche TJ Jr, Laird PW, Baty JD, Fulton LL, Fulton R, et al. Genomic and epigenomic landscapes of adult de novo acute myeloid leukemia. N Engl J Med. 2013; 368:2059-2074. https://doi.org/10.1056/NEJMoa1301689. [PubMed]

15. Salmena L, Shaw P, Fans I, McLaughlin, Rosen B, Risch H, Mitchell C, Sun P, Narod SA, Kotsopoulos J. Prognostic value of INPP4B protein immunohistochemistry in ovarian cancer. Eur J Gynaecol Oncol. 2015; 36:260-267. [PubMed]

16. Rynkiewicz NK, Fedele CG, Chiam K, Gupta R, Kench JG, Ooms LM, McLean CA, Giles GG, Horvath LG, Mitchell CA. INPP4B is highly expressed in prostate intermediate cells and its loss of expression in prostate carcinoma predicts for recurrence and poor long term survival. Prostate. 2015; 75:92-102. https://doi.org/10.1002/ pros.22895. [PubMed]

17. Li Chew C, Lunardi A, Gulluni F, Ruan DT, Chen M, Salmena L, Nishino M, Papa A, Ng C, Fung J, Clohessy JG, Sasaki J, Sasaki T, et al. In Vivo Role of INPP4B in Tumor and Metastasis Suppression through Regulation of PI3K-AKT Signaling at Endosomes. Cancer Discov. 2015; 5:740-751. https://doi.org/10.1158/2159-8290.CD-14-1347. [PubMed]

18. Chen M, Nowak DG, Trotman LC. Molecular pathways: PI3K pathway phosphatases as biomarkers for cancer prognosis and therapy. Clin Cancer Res. 2014; 20:3057-3063. https://doi. org/10.1158/1078-0432.CCR-12-3680. [PubMed]

19. Kofuji S, Kimura H, Nakanishi H, Nanjo H, Takasuga S, Liu H, Eguchi S, Nakamura R, Itoh R, Ueno N, Asanuma $\mathrm{K}$, Huang M, Koizumi A, et al. INPP4B is a PtdIns $(3,4,5)$ P3 phosphatase that can act as a tumor suppressor. Cancer Discov. 2015; 5:730-739. https://doi.org/10.1158/21598290.CD-14-1329. [PubMed]

20. Yuen JW, Chung GT, Lun SW, Cheung CC, To KF, Lo KW. Epigenetic inactivation of inositol polyphosphate 4-phosphatase B (INPP4B), a regulator of PI3K/AKT signaling pathway in EBV-associated nasopharyngeal carcinoma. PLoS One. 2014; 9:e105163. https://doi. org/10.1371/journal.pone.0105163. [ubMed]

21. Zhang L, Zeng D, Chen Y, Li N, Lv Y, Li Y, Xu X, Xu G. miR-937 contributes to the lung cancer cell proliferation by targeting INPP4B. Life Sci. 2016; 155:110-115. https://doi. org/10.1016/j.1fs.2016.05.014. [PubMed]

22. Ip LRH, Poulogiannis G, Viciano FC, Sasaki J, Kofuji S, Spanswick VJ, Hochhauser D, Hartley JA, Sasaki T, Gewinner CA. Loss of INPP4B causes a DNA repair defect through loss of BRCA1, ATM and ATR and can be targeted with PARP inhibitor treatment. Oncotarget. 2015; 6:10548-10562. https:// doi.org/10.18632/oncotarget.3307. [PubMed]

23. Hsu I, Yeh CR, Slavin S, Miyamoto H, Netto GJ, Tsai YC, Muyan M, Wu XR, Messing EM, Guancial EA, Yeh S. Estrogen receptor alpha prevents bladder cancer via INPP4B inhibited akt pathway in vitro and in vivo.
Oncotarget. 2014; 5:7917-7935. https://doi.org/10.18632/ oncotarget.1421. [PubMed]

24. Tokunaga E, Yamashita N, Kitao H, Tanaka K, Taketani K, Inoue Y, Saeki H, Oki E, Oda Y, Maehara Y. Biological and clinical significance of loss of heterozygosity at the INPP4B gene locus in Japanese breast cancer. Breast. 2016; 25:62-68. https://doi.org/10.1016/j.breast.2015.10.006. [PubMed]

25. Ooms LM, Binge LC, Davies EM, Rahman P, Conway JR, Gurung R, Ferguson DT, Papa A, Fedele CG, Vieusseux JL, Chai RC, Koentgen F, Price JT, et al. The Inositol Polyphosphate 5-Phosphatase PIPP Regulates AKT1-Dependent Breast Cancer Growth and Metastasis. Cancer Cell. 2015; 28:155-169. https://doi.org/10.1016/j. ccell.2015.07.003. [PubMed]

26. Gilby DC, Goodeve AC, Winship PR, Valk PJ, Delwel R, Reilly JT. Gene structure, expression profiling and mutation analysis of the tumour suppressor SHIP1 in Caucasian acute myeloid leukaemia. Leukemia. 2007; 21:2390-2393. https://doi.org/10.1038/sj.leu.2404864. [PubMed]

27. Prasad NK, Tandon M, Badve S, Snyder PW, Nakshatri H. Phosphoinositol phosphatase SHIP2 promotes cancer development and metastasis coupled with alterations in EGF receptor turnover. Carcinogenesis. 2008; 29:25-34. https://doi.org/10.1093/carcin/bgm213. [PubMed]

28. Rudge SA, Wakelam MJ. Phosphatidylinositolphosphate phosphatase activities and cancer. J Lipid Res. 2016; 57:176-192. https://doi.org/10.1194/jlr.R059154. [PubMed]

29. Rodgers SJ, Ferguson DT, Mitchell CA, Ooms LM. Regulation of PI3K effector signalling in cancer by the phosphoinositide phosphatases. Biosci Rep. 2017; 37. https://doi.org/10.1042/BSR20160432. [PubMed]

30. Ferron M, Boudiffa M, Arsenault M, Rached M, Pata M, Giroux S, Elfassihi L, Kisseleva M, Majerus PW, Rousseau F, Vacher J. Inositol polyphosphate 4-phosphatase B as a regulator of bone mass in mice and humans. Cell Metab. 2011; 14:466-477. https://doi.org/10.1016/j. cmet.2011.08.013. [PubMed]

31. Vo TT, Fruman DA. INPP4B is a tumor suppressor in the context of PTEN deficiency. Cancer Discov. 2015; 5:697-700. https://doi.org/10.1158/2159-8290.CD-15-0609. [PubMed]

32. Dzneladze I, He R, Woolley JF, Son MH, Sharobim MH, Greenberg SA, Gabra M, Langlois C, Rashid A, Hakem A, Ibrahimova N, Arruda A, Löwenberg B, et al. INPP4B overexpression is associated with poor clinical outcome and therapy resistance in acute myeloid leukemia. Leukemia. 2015; 29:1485-1495. https://doi.org/10.1038/leu.2015.51. [PubMed]

33. Rijal S, Fleming S, Cummings N, Rynkiewicz NK, Ooms LM, Nguyen NY, Teh TC, Avery S, McManus JF, Papenfuss AT, McLean C, Guthridge MA, Mitchell CA, et al. Inositol polyphosphate 4-phosphatase II (INPP4B) is associated with chemoresistance and poor outcome in AML. Blood. 2015; 125:2815-2824. https://doi.org/10.1182/ blood-2014-09-603555. [PubMed] 
34. Guo ST, Chi MN, Yang RH, Guo XY, Zan LK, Wang CY, Xi YF, Jin L, Croft A, Tseng HY, Yan XG, Farrelly M, Wang $\mathrm{FH}$, et al. INPP4B is an oncogenic regulator in human colon cancer. Oncogene. 2016; 35:3049-3061. https://doi. org/10.1038/onc.2015.361. [PubMed]

35. Chen Y, Sun Z, Qi M, Wang X, Zhang W, Chen C, Liu J, Zhao W. INPP4B restrains cell proliferation and metastasis via regulation of the PI3K/AKT/SGK pathway. J Cell Mol Med. 2018; 22:2935-2943. https://doi.org/10.1111/ jemm.13595. [PubMed]

36. Jin H, Yang L, Wang L, Yang Z, Zhan Q, Tao Y, Zou Q, Tang Y, Xian J, Zhang S, Jing Y, Zhang L. INPP4B promotes cell survival via SGK3 activation in NPM1-mutated leukemia. J Exp Clin Cancer Res. 2018; 37:8. https://doi.org/10.1186/ s13046-018-0675-9. [PubMed]

37. Gasser JA, Inuzuka H, Lau AW, Wei W, Beroukhim $\mathrm{R}$, Toker A. SGK3 mediates INPP4B-dependent PI3K signaling in breast cancer. Mol Cell. 2014; 56:595-607. https://doi.org/10.1016/j.molcel.2014.09.023. [PubMed]

38. Chi MN, Guo ST, Wilmott JS, Guo XY, Yan XG, Wang CY, Liu XY, Jin L, Tseng HY, Liu T, Croft A, Hondermarck H, Scolyer R, et al. INPP4B is upregulated and functions as an oncogenic driver through SGK3 in a subset of melanomas. Oncotarget. 2015; 6:39891-39907. https://doi.org/10.18632/ oncotarget.5359. [PubMed]

39. Chen L, Cao Y, Rong D, Wang Y, Cao Y. MicroRNA-605 functions as a tumor suppressor by targeting INPP4B in melanoma. Oncol Rep. 2017; 38:1276-1286. https://doi. org/10.3892/or.2017.5740. [PubMed]

40. Noda T, Matsunaga K, Taguchi-Atarashi N, Yoshimori T. Regulation of membrane biogenesis in autophagy via PI3P dynamics. Semin Cell Dev Biol. 2010; 21:671-676. https:// doi.org/10.1016/j.semcdb.2010.04.002. [PubMed]

41. Perez-Lorenzo R, Gill KZ, Shen CH, Zhao FX, Zheng B, Schulze HJ, Silvers DN, Brunner G, Horst BA. A tumor suppressor function for the lipid phosphatase INPP4B in melanocytic neoplasms. J Invest Dermatol. 2014;
134:1359-1368. $\quad$ https://doi.org/10.1038/jid.2013.511. [PubMed]

42. Dzneladze I, Woolley JF, Rossell C, Han Y, Rashid A, Jain M, Reimand J, Minden MD, Salmena L. SubID, a nonmedian dichotomization tool for heterogeneous populations, reveals the pan-cancer significance of INPP4B and its regulation by EVI1 in AML. PLoS One. 2018; 13:e0191510. https://doi.org/10.1371/journal.pone.0191510. [PubMed]

43. Woolley JF, Dzneladze I, Salmena L. Phosphoinositide signaling in cancer: INPP4B Akt(s) out. Trends Mol Med. 2015; 21:530-532. https://doi.org/10.1016/j. molmed.2015.06.006. [PubMed]

44. Serrano M, Lin AW, McCurrach ME, Beach D, Lowe $\mathrm{SW}$. Oncogenic ras provokes premature cell senescence associated with accumulation of p53 and p16INK4a. Cell. 1997; 88:593-602. https://doi.org/10.1016/s00928674(00)81902-9. [PubMed]

45. de Stanchina E, McCurrach ME, Zindy F, Shieh SY, Ferbeyre G, Samuelson AV, Prives C, Roussel MF, Sherr CJ, Lowe SW. E1A signaling to p53 involves the p19(ARF) tumor suppressor. Genes Dev. 1998; 12:2434-2442. https:// doi.org/10.1101/gad.12.15.2434. [PubMed]

46. Ivetac I, Gurung R, Hakim S, Horan KA, Sheffield DA, Binge LC, Majerus PW, Tiganis T, Mitchell CA. Regulation of PI(3)K/Akt signalling and cellular transformation by inositol polyphosphate 4-phosphatase-1. EMBO Rep. 2009; 10:487-493. https://doi.org/10.1038/embor.2009.28. [PubMed]

47. Wang P, Ma D, Wang J, Fang Q, Gao R, Wu W, Cao L, Hu $\mathrm{X}$, Zhao J, Li Y. INPP4B-mediated DNA repair pathway confers resistance to chemotherapy in acute myeloid leukemia. Tumour Biol. 2016; 37:12513-12523. https://doi. org/10.1007/s13277-016-5111-1. [PubMed] 